\title{
Organelle isolation: functional mitochondria from mouse liver, muscle and cultured filroblasts
}

\author{
Christian Frezza, Sara Cipolat \& Luca Scorrano \\ Dulbecco-Telethon Institute, Venetian Institute of Molecular Medicine, Via Orus 2, 35129 Padova, Italy. Correspondence should be addressed to \\ L.S. (luca.scorrano@unipd.it).
}

Published online 22 February 2007; doi:10.1038/nprot.2006.478

\begin{abstract}
Mitochondria participate in key metabolic reactions of the cell and regulate crucial signaling pathways including apoptosis. Although several approaches are available to study mitochondrial function in situ are available, investigating functional mitochondria that have been isolated from different tissues and from cultured cells offers still more unmatched advantages. This protocol illustrates a step-by-step procedure to obtain functional mitochondria with high yield from cells grown in culture, liver and muscle. The isolation procedures described here require 1-2 hours, depending on the source of the organelles. The polarographic analysis can be completed in 1 hour.
\end{abstract}

\section{INTRODUCTION}

Mitochondria are central organelles controlling the life and death of the cell. They participate in key metabolic reactions, synthesize most of the ATP and regulate a number of signaling cascades, including apoptosis ${ }^{1}$.

Since the early years of "hard-core" bioenergetics when mechanisms behind energy conservation were avidly investigated, mitochondrial research has benefited from the availability of preparations of organelles isolated from tissues. We owe this to the pioneering work of George Palade and coworkers, who in the late 1940s developed a protocol to isolate mitochondria, based on differential centrifugation ${ }^{2}$. They built on the earlier work of Bensley and Hoerr ${ }^{3}$, who isolated a mixed membranous fraction by centrifugation from freeze-thawed guinea-pig liver that was probably enriched in mitochondria. The intuition of Palade was to apply differential centrifugation to allow for separation of the constituents of the cell based on their different sedimentation properties following mechanical homogenization of the tissue. This approach was a real Copernican revolution for mitochondrial research, allowing the isolation of pure organelles with high yields. As a practical consequence, in the subsequent 20 years, we saw such amazing discoveries: the mechanism of energy conservation ${ }^{4}$; the identification of mitochondrial $\mathrm{DNA}^{5,6}$ and of import of mitochondrial precursor proteins ${ }^{7}$; the definition of mitochondrial ultrastructure, with the development of the so-called "Palade's model"; ; and last but not least, the discovery of inner mitochondrial membrane channels 9 .

After almost 15 years during which mitochondria left the center stage of biomedical research, they made their grand reentrée in the 1990s, following the discovery that they amplify apoptosis by releasing cytochrome $c$ and other intermembrane space proteins required to activate fully effector caspases ${ }^{10,11}$. Although it appears clear that mitochondria play a crucial role in apoptosis, the precise mechanism by which cytochrome $c$ is released remains a matter of intense debate and research ${ }^{12}$. Moreover, evidence is mounting on the role of this organelle in several pathophysiological processes, including neurodegeneration ${ }^{13}$, neuronal morphogenesis and plasticity $^{14}$ and infertility ${ }^{15}$. These findings, added to the results of old and new areas of research, aimed at unraveling the basic biological mechanisms of mitochondrial function. From the transport of metabolites and ions, to the elucidation of the mechanisms and proteins involved in protein import, and to the dynamic behavior of mitochondria, all of these fields benefit greatly from the availability of isolated, pure organelles.

This protocol describes how to obtain functional, purified, intact mitochondria from three different sources: liver $^{16}$, skeletal muscle ${ }^{17}$ and cultured cells ${ }^{18}$. These variants intend to be exemplificative and not exhaustive, as they do not cover the different sources from which mitochondria can be isolated. For example, isolation of mitochondria from yeast cells is tailored on the mechanical and osmotic characteristics of these lower eucaryotes ${ }^{19}$. Since our intention is to give a general framework for different organs and for cultured cells that can be in any case modified by the individual researcher, following exactly these protocols is best suited only for isolation of organelles from the described tissues and cells. However, our experience indicates that the protocol used with fibroblasts can be adopted without modification to isolate mitochondria from other cell lines such as HeLa and the prostate cancer cell line LnCaP. On the other hand, the protocols to isolate mitochondria from organs other than muscle and liver differ from the ones described here. We therefore strongly advise the reader to refer to published protocols specific for brain ${ }^{20}$, brown adipose tissue ${ }^{21}$, and heart ${ }^{22}$.

It should be stressed that protocols available to isolate mitochondria are somewhat differ from ours, especially in the speeds of the differential centrifugation steps and in the sugar used as osmolyte in the isolation buffer. While in our experience small changes in the sedimentation speeds ( 600 vs. $800 g, 7,000$ vs. $8,000 g$ ) do not affect quality and yield of the mitochondrial preparation, it has been reported that the use of monosaccharides such as mannitol results in better coupled isolated mitochondria ${ }^{23,24}$. In our experience the use of mannitol did not improve the quality of our mitochondrial preparations. Should the reader find that quality or yield of mitochondria isolated using our protocol is unsatisfactory, it is advisable to try to substitute sucrose with a monosaccharide like mannitol. The ultimate goal of a mitochondrial isolation is to obtain organelles as pure and as functional as possible. We strongly advise, especially if mitochondria are used in functional assays (e.g., release of cytochrome $c$, mitochondrial fusion, protein import and 
production of reactive oxygen species), to always measure the coupling of the preparation using an oxygen electrode. These protocols therefore end with a description of how to measure mitochondrial respiration to ascertain the quality of the preparation. Well-coupled mitochondria are the first step to achieving reliable, reproducible results in assays aimed at investigating the mechanisms of mitochondrial involvement in complex biological phenomena.
In conclusion, these protocols represent a valuable starting point to obtain pure mitochondria from tissues and cells. Isolated mitochondria can then be used to study the function of the organelle, response to apoptotic stimuli, characteristics of cytochrome $c$ release, protein import and many other aspects of mitochondrial biology and pathophysiology that require a source of pure and functional organelles.

\section{MATERIALS}

\section{REAGENTS}

- Cell line of interest or liver or muscle isolated from mice

- Mice of the desired genetic background (Charles River or Jackson

Laboratories)

- Dulbecco's phosphate-buffered saline without $\mathrm{Ca}^{2+}$ and $\mathrm{Mg}^{2+}$

(PBS, Invitrogen, cat. no. 14200-067)

- Sucrose (Sigma, cat. no. 84100)

- Potassium phosphate monobasic (Pi, Sigma, cat. no. P5379)

- Sigma7-9 (Tris, Sigma, cat. no. T1378)

-4-Morpholinepropanesulfonic acid (MOPS; Sigma, cat. no. M1254)

- Disodium ethylenediaminetetraacetate dihydrate (EDTA; Sigma, cat. no. ED2SS)

-Ethylene-bis(oxyethylenenitrilo)tetraacetic acid (EGTA; Sigma, cat. no. E4378)

- Potassium chloride (Baker, cat. no. 0208)

- Magnesium chloride hexahydrate (Sigma, cat. no. M9272)

- Bovine serum albumin (BSA; Sigma, cat. no. A6003)

- Dulbecco's modified Eagle’s medium (Invitrogen, cat. no. 11971025)

- $200 \mathrm{mM}$ L-glutamine (Invitrogen, cat. no. 25030024),

- Fetal bovine serum (Invitrogen, cat. no. 10270106)

$\cdot 5,000 \mathrm{U} \mathrm{ml}^{-1}$ penicillin/5,000 $\mu \mathrm{g} \mathrm{ml}^{-1}$ streptomycin (Invitrogen, cat. no. 15070063)

- $10 \mathrm{mM}$ minimal essential medium nonessential amino-acid solution

(Invitrogen, cat. no. 11140)

- $0.25 \%$ (w/v) trypsin-EDTA solution (Invitrogen, cat. no. 25200072)

- Adenosine 5'-diphosphate sodium salt (ADP; Sigma, cat. no. A2754)

- Carbonyl cyanide 4-(trifluoromethoxy)phenylhydrazone (FCCP; Sigma, cat. no. C2920)

- Glutamic acid (Sigma, cat. no. 27647)

- Malic acid (Sigma, cat. no. M1000)

- Succinic acid (Sigma, cat. no. S3674)

- Rotenone (Sigma, cat. no. R8875)

- L-Ascorbic acid (Sigma, cat. no. 255564)

- $N, N, N, N$-Tetramethyl- $p$-phenylenediamine dihydrochloride (TMPD; Sigma, cat. no. T3134)

- Antimycin A (Sigma, cat. no. A8674)

\section{EQUIPMENT}

- $500 \mathrm{~cm}^{2}$ dishes for cell culture (Nunclon, cat. no. 166508 )

$\cdot 18$-cm cell scrapers (Falcon, cat. no. 353085)

-Motor-driven tightly fitting glass/Teflon Potter Elvehjem homogenizer

(Fig. 1)

- Clark-type oxygen electrode (Hansatech Oxygraph; Fig. 2)

- $50 \mathrm{ml}$ polypropylene Falcon tubes

- $14 \mathrm{ml}$ polypropylene Falcon tubes

$\cdot 1.5 \mathrm{ml}$ microfuge test tube

- $30 \mathrm{ml}$ round-bottomed glass centrifuge tube (Kimble, cat. no. 45500-30)

- Rubber adapter sleeve for centrifuge tube (Kimble, cat. no. 45500-15)

- Refrigerated centrifuge for $50 \mathrm{ml}$ Falcon tubes and glass centrifuge tube

- Hamilton syringe: $10 \mu \mathrm{l}$ (Hamilton, cat. no. $701 \mathrm{~N}$ ) and $50 \mu \mathrm{l}$ (Hamilton cat. no. $705 \mathrm{~N}$ )

REAGENT SETUP

Cell culture medium Use the medium recommended for your favorite cell line. For the cell lines mentioned in this protocol, use Dulbecco's modified Eagle's medium supplemented with $10 \%(\mathrm{v} / \mathrm{v})$ fetal bovine serum, $0.1 \mathrm{mM}$ minimal essential medium nonessential amino acids, $2 \mathrm{mM}$ L-glutamine, penicillin-streptomycin $50 \mathrm{U} \mathrm{ml}^{-1}$ and $50 \mu \mathrm{g} \mathrm{ml}^{-1}$, respectively.

Cells Two or three days before performing the experiments, plate cells in $500 \mathrm{~cm}^{2}$ tissue-culture dishes. Use $70 \mathrm{ml}$ of cell culture medium for each plate.
$\Delta$ CRITICAL Ensure that the cells are spread thoroughly wide on the plates: for high yield of isolated mitochondria, it is crucial to reach almost $100 \%$ confluence on the day of the experiment.

$1 \mathrm{M}$ sucrose Dissolve $342.3 \mathrm{~g}$ of sucrose in 1 liter of distilled water; mix well and prepare $20 \mathrm{ml}$ aliquots; store them at $-20{ }^{\circ} \mathrm{C}$.

0.1 M Tris/MOPS Dissolve $12.1 \mathrm{~g}$ of Tris in $500 \mathrm{ml}$ of distilled water, adjust $\mathrm{pH}$ to 7.4 using MOPS powder, bring the solution to 1 liter and store at $4{ }^{\circ} \mathrm{C}$. $1 \mathrm{M}$ Tris/HCl Dissolve $121.14 \mathrm{~g}$ of Tris in $500 \mathrm{ml}$ of distilled water, adjust $\mathrm{pH}$ to 7.4 using $\mathrm{HCl}$; bring the solution to 1 liter and store at room temperature. 0.1 M EGTA/Tris Dissolve $38.1 \mathrm{~g}$ of EGTA in $500 \mathrm{ml}$ of distilled water, adjust $\mathrm{pH}$ to 7.4 using Tris powder, bring the solution to 1 liter and store at $4{ }^{\circ} \mathrm{C}$. $0.5 \mathrm{M} \mathrm{MgCl}_{2}$ Dissolve $101.7 \mathrm{~g}$ of $\mathrm{MgCl}_{2}$ in 1 liter of distilled water and store at $4{ }^{\circ} \mathrm{C}$

$1 \mathrm{M} \mathrm{KCl}$ Dissolve $74.6 \mathrm{~g}$ of $\mathrm{KCl}$ in 1 liter of distilled water and store at $4{ }^{\circ} \mathrm{C}$.

1 M EDTA Dissolve $372.2 \mathrm{~g}$ of EDTA in $500 \mathrm{ml}$ of distilled water, adjust $\mathrm{pH}$ to 7.4 using Tris powder, bring the solution to 1 liter and store at $4{ }^{\circ} \mathrm{C}$.

10\% BSA Dissolve $10 \mathrm{~g}$ of BSA in $100 \mathrm{ml}$ of distilled water and store at $-20^{\circ} \mathrm{C}$. $1 \mathrm{M} \mathrm{Pi}$ Dissolve $136.1 \mathrm{~g}$ of $\mathrm{KH}_{2} \mathrm{PO}_{4}$ in $500 \mathrm{ml}$ of distilled water, adjust $\mathrm{pH}$ to 7.4 using Tris powder, bring the solution to 1 liter and store at $4{ }^{\circ} \mathrm{C}$.

$10 \mathrm{mM}$ ADP Dissolve $4.7 \mathrm{mg}$ of ADP in $1 \mathrm{ml}$ of distilled water. Adjust $\mathrm{pH}$ to 7.4, prepare $100 \mu \mathrm{l}$ aliquots and store in the dark at $-20^{\circ} \mathrm{C}$ for up to 6 months. $20 \mathrm{mM}$ FCCP Dissolve $5.1 \mathrm{mg}$ of FCCP in $1 \mathrm{ml}$ of absolute ethanol. The color of the solution is faint yellow. Store at $-20{ }^{\circ} \mathrm{C}$. Dilute the stock solution to $100 \mu \mathrm{M}$ by adding $10 \mu \mathrm{l}$ of $20 \mathrm{mM}$ FCCP in $2 \mathrm{ml}$ of absolute ethanol, just prior to use.

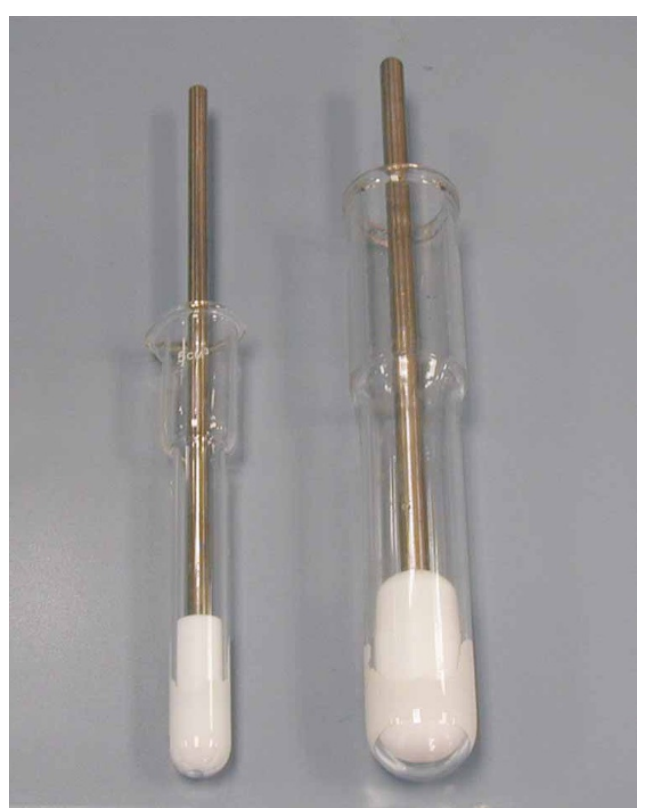

Figure 1 | Glass/Teflon Potter Elvehjem homogenizers. The homogenizer on the left $(5 \mathrm{ml})$ is most suitable for isolation of mitochondria from cells, whereas the one on the right $(30 \mathrm{ml})$ is more appropriate for isolation from tissues. 


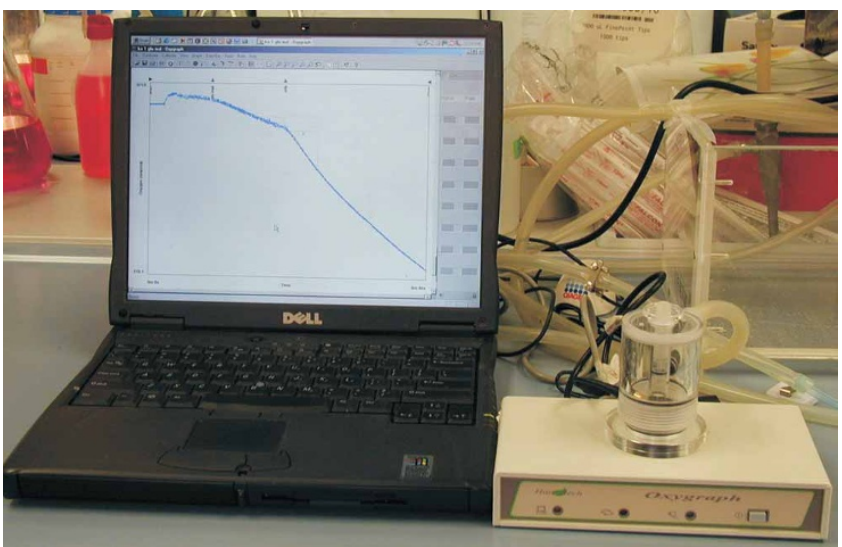

Figure 2 | A Clarke-type oxygen electrode connected to a laptop and a water bath. The trace on the screen corresponds to the recording of the experiment running when the photograph was taken.

0.25 M glutamate/0.125 M malate Dissolve $9.2 \mathrm{~g}$ of glutamic acid and $4.2 \mathrm{~g}$ of malic acid in $100 \mathrm{ml}$ of distilled water. Adjust $\mathrm{pH}$ to 7.4 with Tris base to achieve complete dissolution of the salts. Add water to bring the volume to $250 \mathrm{ml}$, prepare $10 \mathrm{ml}$ aliquots and store at $-20{ }^{\circ} \mathrm{C}$ for up to 6 months.

$0.5 \mathrm{M}$ succinate stock solution $(100 \times)$ Dissolve $3.0 \mathrm{~g}$ of succinic acid in $30 \mathrm{ml}$ of distilled water. Adjust $\mathrm{pH}$ with Tris base to achieve complete solubilization of the salts. Add water to make up the volume to $50 \mathrm{ml}$, prepare $10 \mathrm{ml}$ aliquots and store at $-20{ }^{\circ} \mathrm{C}$ for up to 6 months.

$2 \mathrm{mM}$ rotenone stock solution Dissolve $4.7 \mathrm{mg}$ of rotenone in $6 \mathrm{ml}$ of absolute ethanol. Mix well for complete dissolution. $\triangle$ CRITICAL Rotenone in organic solvents decomposes and is oxidized upon exposure to light and air. The solution, previously transparent, becomes brownish. It is imperative to protect the stock solution from direct light using an aluminum foil. ! CAUTION Rotenone is highly toxic: avoid skin contact and inhalation.

\section{PROCEDURE}

1) Mitochondria can be isolated from a variety of cells or tissues. Option A describes isolation of mitochondria from mouse embryonic fibroblasts (MEFs) (see Fig. 3 for a timeline); option $B$ describes isolation of mitochondria from mouse liver (see Fig. 4 for a timeline); and option $C$ describes isolation of mitochondria from mouse skeletal muscle (see Fig. 5 for a timeline).

\section{(A) Isolation of mitochondria from MEFs TIMING approximately $\mathbf{2} \mathbf{h}$}

(i) Remove the medium from the cells and wash the cells once with PBS.

(ii) Remove PBS and detach the cells using a cell scraper.

(iii) Transfer the cell suspension to a $50 \mathrm{ml}$ polypropylene Falcon tube.

(iv) Wash the plate once with PBS and scrape the dish to detach the remaining cells.

(v) Transfer the cells to the same polypropylene Falcon tube defined in Step 3. In our experience, seeding $120 \times 10^{6}$ MEFs per dish 2 days before the experiment results in a good yield of mitochondria (approximately $3 \mathrm{mg}$ of mitochondrial protein).

(vi) Centrifuge cells at $600 \mathrm{~g}$ at $4{ }^{\circ} \mathrm{C}$ for $10 \mathrm{~min}$.

(vii) Discard the supernatant and resuspend cells in $3 \mathrm{ml}$ of ice-cold $\mathrm{IB}_{\mathrm{c}}$.
$600 \mathrm{mM}$ ascorbate stock solution Dissolve $5.2 \mathrm{~g}$ of ascorbic acid in $50 \mathrm{ml}$ of distilled water, adjust $\mathrm{pH}$ to 7.4 and store at $-20{ }^{\circ} \mathrm{C}$ for up to 6 months. $30 \mathrm{mM}$ TMPD stock solution Dissolve $0.36 \mathrm{~g}$ of TMPD in $50 \mathrm{ml}$ of distilled water; adjust $\mathrm{pH}$ to 7.4 ; store at $-20{ }^{\circ} \mathrm{C}$ for up to 6 months. The color of the solution is deep blue owing to the oxidation of the compound by oxygen. $25 \mathrm{mg} \mathrm{ml}^{-1}$ antimycin A stock solution Dissolve $50 \mathrm{mg}$ of antimycin A in $2 \mathrm{ml}$ of absolute ethanol. Dilute the stock solution to $25 \mu \mathrm{g} \mathrm{ml}^{-1}$, by adding $2 \mu \mathrm{l}$ of $25 \mathrm{mg} \mathrm{ml}^{-1}$ Antimycin A in $2 \mathrm{ml}$ of absolute ethonal, just prior to use. ! CAUTION Antimycin A is highly toxic: avoid skin contact and inhalation. Buffer for cell and mouse liver mitochondria isolation $\left(\mathrm{IB}_{\mathbf{c}}\right)$ Prepare $100 \mathrm{ml}$ of IB by adding $10 \mathrm{ml}$ of $0.1 \mathrm{M}$ Tris-MOPS and $1 \mathrm{ml}$ of EGTA/Tris to $20 \mathrm{ml}$ of 1 $\mathrm{M}$ sucrose. Bring the volume to $100 \mathrm{ml}$ with distilled water. Adjust $\mathrm{pH}$ to 7.4. Buffer 1 for muscle mitochondria isolation $\left(I_{m} 1\right)$ Prepare $100 \mathrm{ml}$ of $I B_{m} 1$ by mixing $6.7 \mathrm{ml}$ of $1 \mathrm{M}$ sucrose, $5 \mathrm{ml}$ of $1 \mathrm{M}$ Tris/ $\mathrm{HCl}, 5 \mathrm{ml}$ of $1 \mathrm{M} \mathrm{KCl}, 1 \mathrm{ml}$ of $1 \mathrm{M}$ EDTA and $2 \mathrm{ml}$ of $10 \% \mathrm{BSA}$. Adjust $\mathrm{pH}$ to 7.4. Bring the volume to $100 \mathrm{ml}$ with distilled water.

Buffer 2 for muscle mitochondria isolation $\left(\mathrm{IB}_{\mathrm{m}} 2\right)$ Prepare $100 \mathrm{ml}$ of $\mathrm{IB}_{\mathrm{m}} 12$ by mixing $25 \mathrm{ml}$ of $1 \mathrm{M}$ sucrose, $3 \mathrm{ml}$ of $0.1 \mathrm{M}$ EGTA/Tris and $1 \mathrm{ml}$ of $1 \mathrm{M}$ Tris/ $\mathrm{HCl}$. Adjust $\mathrm{pH}$ to 7.4. Bring the volume to $100 \mathrm{ml}$ with distilled water. Experimental buffer for cell and mouse-liver mitochondria $\left(\mathrm{EB}_{\mathbf{c}}\right)$ To prepare $100 \mathrm{ml}$ of $\mathrm{EB}_{\mathcal{c}}$, mix $12.5 \mathrm{ml}$ of $1 \mathrm{M} \mathrm{KCl}, 1 \mathrm{ml}$ of $1 \mathrm{M}$ Tris/MOPS, $10 \mathrm{ml}$ of $100 \mu \mathrm{l}$ $0.1 \mathrm{M}$ EGTA/Tris and $100 \mu \mathrm{l}$ of Pi. Adjust $\mathrm{pH}$ to 7.4. Bring the volume to $100 \mathrm{ml}$ with distilled water.

Experimental buffer for muscle mitochondria $\left(\mathbf{E B}_{\mathrm{m}}\right)$ To prepare $100 \mathrm{ml}$ of $\mathrm{EB}_{\mathrm{m}}$, add $1 \mathrm{ml}$ of $1 \mathrm{M}$ Tris/ $\mathrm{HCl}, 1 \mathrm{ml}$ of $0.5 \mathrm{M} \mathrm{MgCl}_{2}, 200 \mu \mathrm{l}$ of $1 \mathrm{M} \mathrm{Pi}$ and $20 \mu \mathrm{l}$ of $0.1 \mathrm{M} \mathrm{EGTA/Tris} \mathrm{to} 25 \mathrm{ml}$ of $1 \mathrm{M}$ sucrose. Adjust $\mathrm{pH}$ to 7.4. Bring the volume to $100 \mathrm{ml}$ with distilled water. $\triangle$ CRITICAL Wash all glassware three times with bidistilled water to avoid $\mathrm{Ca}^{2+}$ contamination. $\mathrm{Ca}^{2+}$ overload is the most common cause for the dysfunction of isolated mitochondria. $\Delta$ CRITICAL Prepare all the buffers the same day of the experiment, to avoid bacterial/yeast growth in stored buffers. $\triangle$ CRITICAL Since $\mathrm{pH}$ depends on temperature, measure the $\mathrm{pH}$ of all solutions at $25^{\circ} \mathrm{C}$.

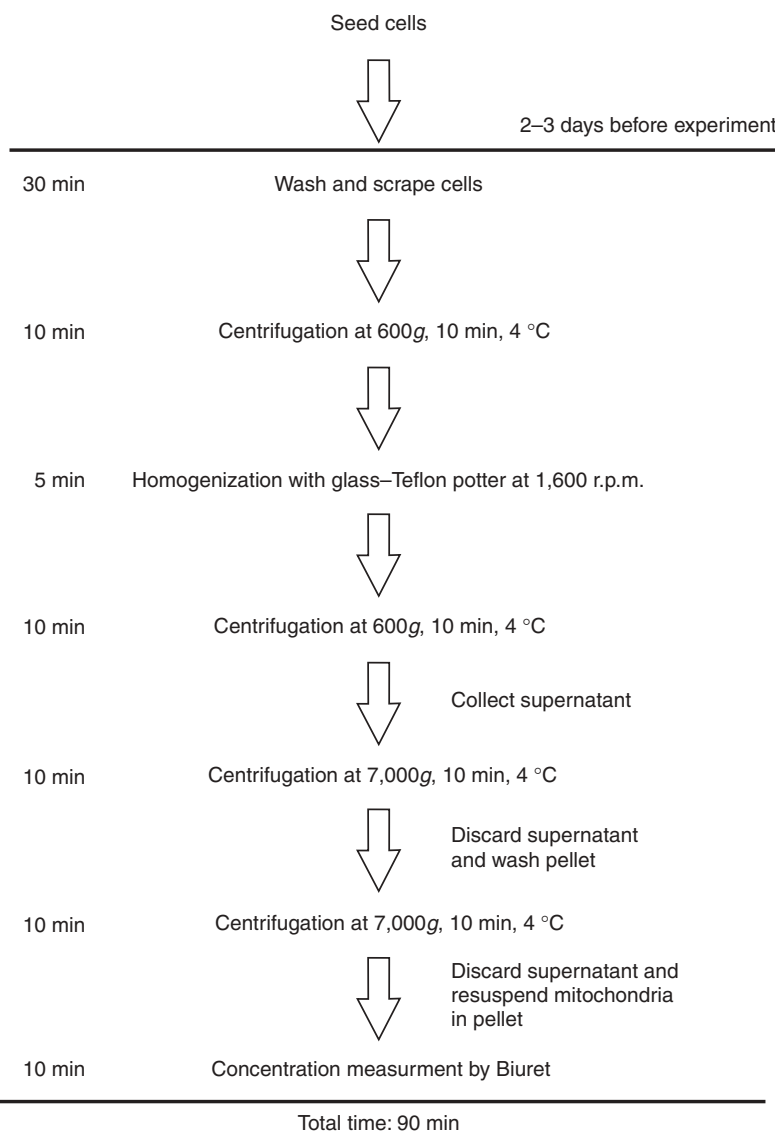

Figure 3 | Timing of isolation of mitochondria from MEFs. 
PROTOCOL

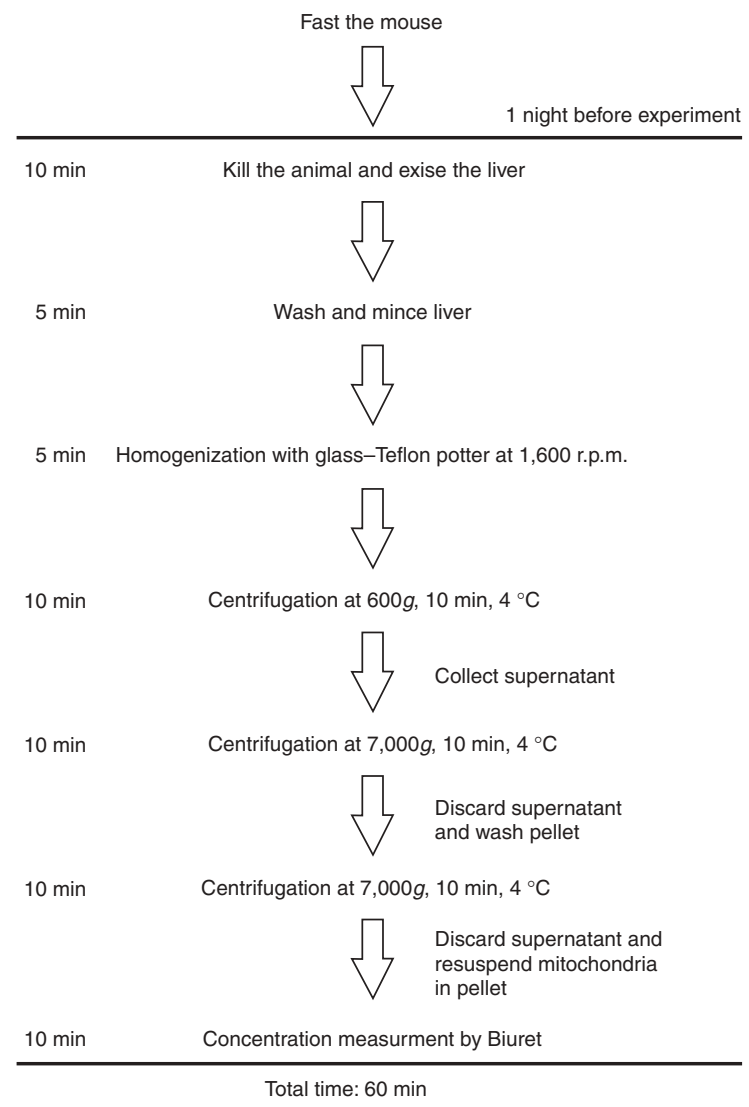

Figure 4 | Timing of isolation of mitochondria from mouse liver.

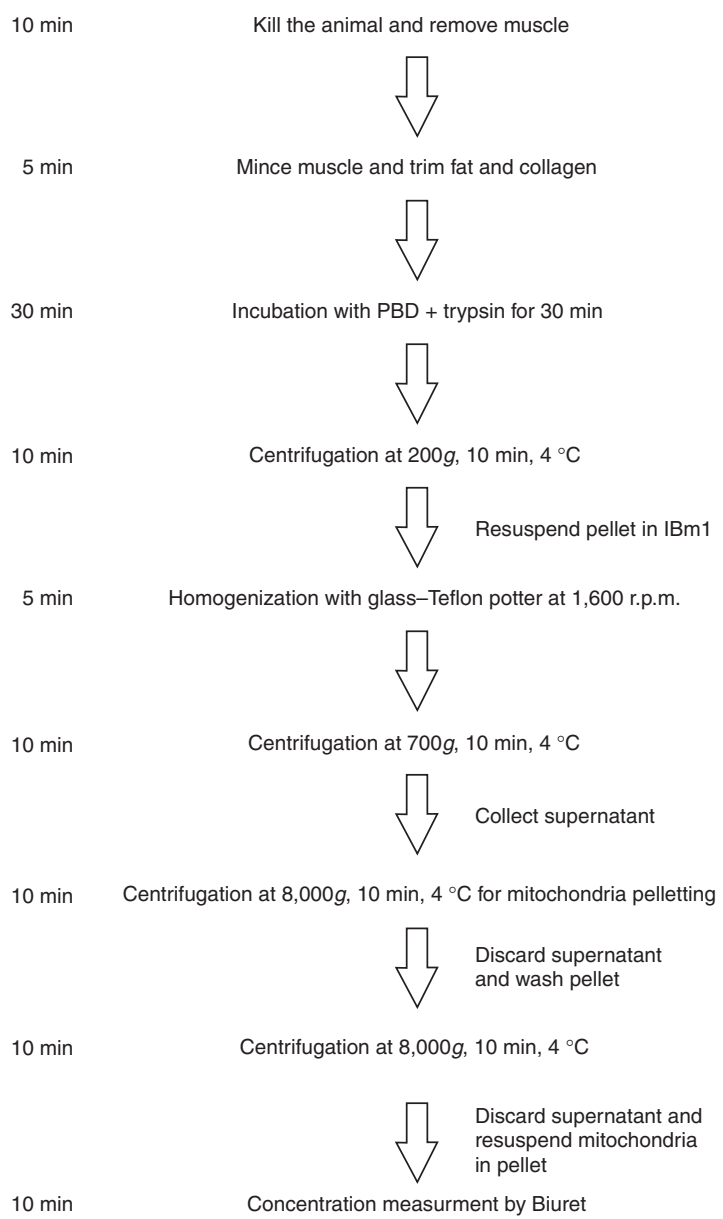

Total time: $100 \mathrm{~min}$

Figure 5 | Timing of isolation of mitochondria from mouse skeletal muscle.

(viii) Homogenize the cells using a Teflon pestle operated at 1,600 r.p.m.; stroke the cell suspension placed in a glass potter 30-40 times the cell suspension placed in a glass potter. $\triangle$ CRITICAL STEP The Teflon-glass coupling represents the best compromise between homogenization of the cells and the preservation of mitochondrial integrity. Harsher techniques, including glass pestle in a glass potter, can easily damage mitochondria.

$\triangle$ CRITICAL STEP Precool the glassware in an ice-bath $5 \mathrm{~min}$ before starting the procedure. Homogenization as well as the following steps must be performed at $4{ }^{\circ} \mathrm{C}$ to minimize the activation of damaging phospholipases and proteases.

I CAUTION Wear protecting gloves while you are using the homogenizer to avoid possible injuries in the unlikely event that the potter breaks down.

? TROUBLESHOOTING

(ix) Transfer the homogenate to a $50 \mathrm{ml}$ polypropylene Falcon tube and centrifuge at $600 \mathrm{~g}$ for $10 \mathrm{~min}$ at $4{ }^{\circ} \mathrm{C}$.

(x) Collect the supernatant, transfer it to a glass centrifuge tube and centrifuge it at $7,000 \mathrm{~g}$ for $10 \mathrm{~min}$ at $4{ }^{\circ} \mathrm{C}$. ? TROUBLESHOOTING

(xi) Discard the supernatant and wash the pellet with $200 \mu \mathrm{l}$ of ice-cold $\mathrm{IB}_{\mathrm{c}}$. Resuspend the pellet in $200 \mu \mathrm{l}$ of ice-cold $\mathrm{IB}_{\mathrm{c}}$ and transfer the suspension to a $1.5 \mathrm{ml}$ microfuge tube.

(xii) Centrifuge the homogenate at $7,000 \mathrm{~g}$ for $10 \mathrm{~min}$ at $4{ }^{\circ} \mathrm{C}$.

(xiii) Discard the supernatant and resuspend the pellet containing mitochondria. You can use a glass rod to loosen the pellet paste. Avoid adding IB and try to resuspend the mitochondria in the small amount of buffer that remains after discarding the supernatant. Use a $200 \mu \mathrm{l}$ pipettor and avoid the formation of bubbles during the resuspension.

(xiv) Transfer the mitochondrial suspension to a microfuge and store it on ice.

$\triangle$ CRITICAL STEP Avoid diluting mitochondria with buffer. Mitochondria retain their functionality for a longer time, probably as a consequence of lower exposure to oxygen, when they are stored in a concentrated form.

(xv) Measure mitochondria concentration using the Biuret methods.

PAUSE POINT Mitochondria are now ready to be used in experiments: use the preparation within 1-3 $\mathrm{h}$ for better functional responses.

$\triangle$ CRITICAL STEP The typical yield of this preparation is $\sim 50 \mathrm{mg} \mathrm{ml}^{-1}$ in a total volume of approximately $0.1 \mathrm{ml}$. 
$\triangle$ CRITICAL STEP The Biuret method for measurement of mitochondrial concentration is accurate in the range of protein concentrations obtained from this protocol; other methods like the Bradford method can be used, but the mitochondrial lysate must be diluted in order to avoid saturation of the probe.

\section{(B) Isolation of mitochondria from mouse liver TIMING approximately $1 \mathrm{~h}$}

(i) Starve the mouse overnight before the isolation experiment.

(ii) Kill an adult mouse (about $30 \mathrm{~g}$ ) by cervical dislocation and rapidly explant the liver from the peritoneal cavity. Find the gallbladder and remove it using a scalpel. Immerse the liver in $50 \mathrm{ml}$ of ice-cold $\mathrm{IB}_{\mathrm{c}}$ in a small beaker.

$\triangle$ CRITICAL STEP Local and national regulations on animal care and handling vary. Check that you hold the appropriate authorization to perform animal experiments.

(iii) Rinse the liver free of blood by using ice-cold $\mathrm{IB}_{\mathrm{c}}$. Usually, four or five washes are sufficient to completely clarify the $\mathrm{IB}_{c}$.

(iv) Mince the liver into small pieces using scissors. This should be performed while keeping the beaker in an ice bath.

(v) Discard the $\mathrm{IB}_{\mathrm{c}}$ used during the mincing and replace it with $5 \mathrm{ml}$ of ice-cold fresh $\mathrm{IB}_{\mathrm{c}}$. Transfer the suspension to the glass potter.

$\triangle$ CRITICAL STEP Homogenization, as well as the following steps, must be performed at $4{ }^{\circ} \mathrm{C}$ to minimize activation of damaging phospholipases and proteases.

(vi) Homogenize the liver using a Teflon pestle operated at 1,600 r.p.m., stroke the minced liver 3-4 times.

$\triangle$ CRITICAL STEP The optimal ratio between tissue and isolation buffer ranges between 1:5 to 1:10 (w:v).

$\triangle$ CRITICAL STEP Precool the glassware in an ice-bath $5 \mathrm{~min}$ before starting the procedure. Homogenization and the

following steps must be performed at $4{ }^{\circ} \mathrm{C}$ to minimize activation of damaging phospholipases and proteases.

! CAUTION Wear protecting gloves while you are using the homogenizer to avoid possible injuries in the unlikely event that the potter breaks down.

? TROUBLESHOOTING

(vii) Transfer the homogenate to a $50 \mathrm{ml}$ polypropylene Falcon tube and centrifuge at $600 \mathrm{~g}$ for $10 \mathrm{~min}$ at $4{ }^{\circ} \mathrm{C}$.

(viii) Transfer the supernatant to glass centrifuge tubes and centrifuge at $7,000 \mathrm{~g}$ for $10 \mathrm{~min}$ at $4{ }^{\circ} \mathrm{C}$. ? TROUBLESHOOTING

(ix) Discard the supernatant and wash the pellet with $5 \mathrm{ml}$ of ice-cold $\mathrm{IB}_{\mathrm{c}}$.

(x) Centrifuge at $7,000 \mathrm{~g}$ for $10 \mathrm{~min}$ at $4{ }^{\circ} \mathrm{C}$.

(xi) Discard the supernatant and resuspend the pellet, containing mitochondria. You can use a glass rod to loosen the pellet paste. Avoid adding IB and try to resuspend the mitochondria in the small amount of buffer that remains after discarding the supernatant. Use a $1 \mathrm{ml}$ pipettor and avoid the formation of bubbles during the resuspension process.

(xii) Transfer mitochondrial suspension into a $14 \mathrm{ml}$ Falcon tube and store on ice.

$\triangle$ CRITICAL STEP Avoid diluting mitochondria with buffer as mitochondria retain their functionality for a longer time when kept concentrated, minimizing exposure to oxygen.

PAUSE POINT Mitochondria are now ready to be used in experiments; use the preparation within 1-3 $\mathrm{h}$ for better functional responses.

(xiii) Measure mitochondrial concentration using the Biuret methods.

$\triangle$ CRITICAL STEP The usual concentration of mitochondria in this kind of preparation is about $80 \mathrm{mg} \mathrm{ml}^{-1}$ and the total volume is about $1 \mathrm{ml}$.

$\triangle$ CRITICAL STEP The Biuret method for measurement of mitochondrial concentration is accurate in the range of protein concentrations obtained from this protocol; other methods like the Bradford method can be used, but the mitochondrial lysate must be diluted in order to avoid saturation of the probe.

(C) Isolation of mitochondria from mouse skeletal muscle $\bigcirc$ TIMING approximately $1.5 \mathrm{~h}$

(i) Kill the mouse by cervical dislocation. Using a scalpel, rapidly remove the skeletal muscles of interest and immerse them in a small beaker containing $5 \mathrm{ml}$ of ice-cold PBS supplemented with $10 \mathrm{mM}$ EDTA. A timeline of this protocol is outlined in Figure 6.

$\triangle$ CRITICAL STEP Local and national regulations on animal care and handling vary. Check that you hold the appropriate authorizations to perform animal experiments.

$\triangle$ CRITICAL STEP The use of EDTA instead of EGTA chelates also $\mathrm{Mg}^{2+}$, which is extremely abundant in muscle tissue (given the high content in ATP). $\mathrm{Mg}^{2+}$ can influence mitochondrial function as well as the kinetics of cytochrome $c$ release ${ }^{25}$.

(ii) Mince the muscles into small pieces using scissors and trim visible fat, ligaments and connective tissue.

(iii) Wash the minced muscles twice or thrice with ice-cold PBS supplemented with $10 \mathrm{mM}$ EDTA.

(iv) Resuspend the minced muscles in $5 \mathrm{ml}$ of ice-cold PBS supplemented with $10 \mathrm{mM}$ EDTA and $0.05 \%$ trypsin for 30 min.

(v) Centrifuge at $200 \mathrm{~g}$ for $5 \mathrm{~min}$ and discard the supernatant.

(vi) Resuspend the pellet in $\mathrm{IB}_{\mathrm{m}} 1$. 
PROTOCOL

(vii) Homogenize the muscles using a Teflon pestle operated at 1,600 r.p.m.; stroke the minced muscle ten times.

$\triangle$ CRITICAL STEP The optimal ratio between tissue and isolation buffer ranges between 1:5 and 1:10 (w:v).

$\triangle$ CRITICAL STEP Precool the glassware in an ice-bath $5 \mathrm{~min}$ before starting the procedure. Homogenization, and the following steps, must be performed at $4{ }^{\circ} \mathrm{C}$ to minimize the activation of damaging phospholipases and proteases.

! CAUTION Wear protecting gloves while you are using the homogenizer to avoid possible injuries in the unlikely event that the potter breaks down.

Precool the glassware in an ice-bath for 5 min before starting the following steps.

? TROUBLESHOOTING

(viii) Transfer the homogenate to a $50 \mathrm{ml}$ polypropylene Falcon tube and centrifuge at $700 \mathrm{~g}$ for $10 \mathrm{~min}$ at $4{ }^{\circ} \mathrm{C}$.

(ix) Transfer the supernatant to glass centrifuge tubes and centrifuge at $8,000 \mathrm{~g}$ for 10 min at $4{ }^{\circ} \mathrm{C}$. ? TROUBLESHOOTING

(x) Discard the supernatant and resuspend the pellet in $5 \mathrm{ml}$ of ice-cold $\mathrm{IB}_{\mathrm{m}} 2$.

(xi) Centrifuge at $8,000 \mathrm{~g}$ for $10 \mathrm{~min}$ at $4{ }^{\circ} \mathrm{C}$.

(xii) Discard the supernatant and resuspend the pellet containing mitochondria. You can use a glass rod to loosen the pellet paste. Avoid adding IB and try to resuspend the mitochondria in the small amount of buffer that remains after discarding the supernatant. Use a $200 \mu \mathrm{l}$ pipettor and avoid the formation of bubbles during the resuspension process.

(xiii) Transfer mitochondrial suspension into a $14 \mathrm{ml}$ Falcon tube and keep it on ice.

(xiv) Measure mitochondrial concentration using the Biuret methods.

$\triangle$ CRITICAL STEP This preparation normally yields $0.8 \mathrm{ml}$ of $50 \mathrm{mg} \mathrm{ml}^{-1}$ mitochondria.

$\triangle$ CRITICAL STEP The Biuret method for measurement of mitochondrial concentration is accurate in the range of protein concentrations obtained from this protocol; other methods like the Bradford method can be used, but the mitochondrial lysate must be diluted in order to avoid saturation of the probe.

\section{Measuring mitochondrial respiration $\bigcirc$ TIMING approximately $1 \mathrm{~h}$}

2| Calibrate the Clarke-type oxygen electrode. Procedures vary from instrument to instrument. You should follow the manufacturer's instructions for the instrument you are using.

3| Equilibrate temperature and oxygen tension of $\mathrm{EBc}$ or $\mathrm{EBm}$ by placing open beakers containing the buffers in the water bath connected to the oxygraph. After 20-30 min, the temperature of the buffers is likely to be in equilibrium with that of the water bath.

4| Add an appropriate volume of EB to the oxygraph chamber. Use $0.5 \mathrm{ml}$ for the mitochondria isolated from cells and 1 or $2 \mathrm{ml}$ for the liver and muscle mitochondria. Close the oxygraph chamber.

5| Start the recording of the oxygen consumption.

$\triangle$ CRITICAL STEP Verify that the recording is stable and that no drifts are apparent. Drifts can mask the oxygen consumption by the mitochondrial preparation and thereby complicate the interpretation of the results.

? TROUBLESHOOTING

6| Wait for 2 min to obtain a stable baseline.

7| Using an appropriate Hamilton microsyringe, add mitochondria to obtain a final concentration of $1 \mathrm{mg} \mathrm{ml}^{-1}$. A fast, transitory decrease in the oxygen content of the chamber will be observed, caused by anaerobiosis of the isolated mitochondria; this will be followed by a slower decrease caused by the respiration of the mitochondria. This is supported by endogenous substrates and is commonly referred to as "state 1 " respiration ${ }^{26}$.

8| Record oxygen consumption till it stops.

! CAUTION In liver mitochondria state 1 respiration commonly does not stop.

TABLE 1 | Substrates and inhibitors of the respiratory chain.

\begin{tabular}{lll}
\hline & Substrate (final concentration) & Inhibitor (final concentration) \\
\hline Complexes I, III, IV & Glutamate $(5 \mathrm{mM}) /$ malate $(2.5 \mathrm{mM})$ & $/ / /$ \\
Complexes II, III, IV & Succinate $(5 \mathrm{mM})$ & Rotenone $(2 \mu \mathrm{M})$ \\
Complex IV & Ascorbate $(6 \mathrm{mM}) /$ TMPD $(300 \mu \mathrm{M})$ & Antimycin A $\left(0.25 \mu \mathrm{gl}^{-1}\right)$ \\
\hline
\end{tabular}

The span of the respiratory chain examined by each combination of substrate/inhibitor is indicated along with the final concentration to use in the oxygraphy experiments. 
9| Using Hamilton microsyringes, add the appropriate concentrations of respiratory substrates and inhibitors for the complexes of the respiratory chain you wish to study (refer to Table 1). The mitochondrial suspension will now start consuming oxygen as a consequence of the basal activity of the respiratory chain in counteracting the inner mitochondrial membrane proton leak. This represents the so-called "state 2 " respiration ${ }^{26}$.

$\triangle$ CRITICAL STEP The rate of oxygen consumption should now be faster than the rate observed with buffer alone. This indicates that you have obtained functional, respiring mitochondria.

\section{? TROUBLESHOOTING}

10| Record for 5 min.

11 Add ADP to obtain a final concentration of 100-150 $\mu$ M. Faster consumption of oxygen will be observed. This has been caused by proton back-diffusion through the stalk portion of the ATPase, which has been compensated by faster electron flow through the respiratory chain to the terminal electron acceptor, $0_{2}$. This is classically referred to as "state 3 " respiration ${ }^{26}$.

$\triangle$ CRITICAL STEP The rate of oxygen consumption should now be faster than the rate observed with substrates alone, indicating that we have obtained well coupled mitochondria. The increase in respiration, observed with ADP, varies from tissue to tissue and from substrate to substrate. As a general rule, and for the sole purpose of quality control of the preparation, the minimum requirements to proceed with the experiment are as follows: using glutamate malate as a substrate, maintaining a ratio of 2 in mitochondria isolated from cell lines and a ratio of 4 in mitochondria isolated from tissues. ? TROUBLESHOOTING

12 Wait until the respiration slows down and returns to a rate comparable to that before the addition of ADP. This is caused by the consumption of the added ADP. The respiration, which follows ADP exhaustion, is classically referred to as "state 4" respiration ${ }^{26}$.

13| Wait for $3 \mathrm{~min}$.

14| Add the uncoupler FCCP to obtain a final concentration of 60-100 nM.

15 The respiration will speed up and reach values slightly higher than those observed during the recording of state-3 respiration. ? TROUBLESHOOTING

16| Record for a further 5 min and then stop recording.

\section{TIMING}

Step 1A: approximately $2 \mathrm{~h}$, depending on the amount of cells to be used; however, cells will need to be seeded 2 or $3 \mathrm{~d}$ in advance to let them grow

Step 1B: approximately $1 \mathrm{~h}$; however the mouse will need to be fasted from the night before

Step 1C: $1.5 \mathrm{~h}$, depending on the amount of muscle to be minced

\section{? TROUBLESHOOTING}

Troubleshooting advice can be found in Table 2 .

TABLE 2 | Troubleshooting table.

\begin{tabular}{llll}
\hline Step & Problem & Possible causes & Solution \\
\hline 1Aviii, & Low yield of isolated & Low cell density during homogenization & Low cell density may result in better homogenization. \\
1Bvi, & mitochondria & & However, mitochondria are usually of lower quality, \\
1Cvii & & probably as a consequence of mechanical damage \\
& & during preparation
\end{tabular}


PROTOCOL

TABLE 2 | Troubleshooting table (continued).

\begin{tabular}{|c|c|c|c|}
\hline Step & Problem & Possible causes & Solution \\
\hline $\begin{array}{l}\text { 1Ax, } \\
\text { 1Bviii, } \\
\text { 1Cix }\end{array}$ & $\begin{array}{l}\text { Low quality of isolated } \\
\text { mitochondria }\end{array}$ & Pellet after centrifugation is lost & $\begin{array}{l}\text { When the supernatant is poured off, the loose upper } \\
\text { part of the mitochondrial pellet may be detached as } \\
\text { well. Intact mitochondria tend to sediment more } \\
\text { quickly than damaged mitochondria. The loose part } \\
\text { of the pellet probably contains a high proportion of } \\
\text { damaged (uncoupled) mitochondria and can be } \\
\text { lost without affecting the overall quality of the } \\
\text { mitochondrial preparation }\end{array}$ \\
\hline
\end{tabular}

1Ax, Low quality of isolated Lipid contamination

1Bvii mitochondria

5 0xygen consumption baseline is not stable

9 Mitochondrial preparation is not consuming oxygen

ADP-stimulated respiration rate is too low lower than ADP-stimulated respiration

The white foamy material near the top of the tube consists of lipids. Mixing of lipids with the mitochondria suspension will cause some degree of uncoupling. Therefore avoid contact with mitochondria: remove the foamy material by wiping the inside of the tube with a Kimwipe

Bacterial or yeast contamination of your buffer

Inadequate calibration of the instrument Tears in the polyethylene membrane of the electrode

Overestimation of final protein concentration (therefore added too little protein in the oxygraph chamber) Mechanical and osmotical damage to mitochondria during isolation Contamination by other intracellular membranes, such as endoplasmic reticulum or nuclei

The most trivial explanation is that you omitted $\mathrm{Pi}$ from your buffer High percentage of mitochondria with ruptured outer membranes that leaked cytochrome $c$

Unusually high basal respiration, as a consequence of uncoupling by $\mathrm{Ca}^{2+}$ overload Unusually high basal respiration, as a consequence of uncoupling by fatty acids

Too much FCCP used
Verify if your buffers are contaminated, by repeating the recording with bidistilled water in the oxygraph chamber

Re-calibrate the instrument

Check response of the oxygraph by transiently stopping stirring: due to the immediate drop in the local oxygen concentration the recording should immediately fall and return to the original baseline only when the stirrer is restarted. If this manoeuvre does not give the expected results, inspect and if necessary substitute the membrane of the electrode

Try to double mitochondrial concentration in the chamber

Substitute $0.2 \mathrm{M}$ sucrose with $0.3 \mathrm{M}$ mannitol in the isolation buffer

In steps $1 \mathrm{Axi}, 1 \mathrm{Bix}$ or $1 \mathrm{Cx}$, wash the mitochondrial pellet with twice the amount of isolation buffer

Add $\mathrm{Pi}$ and check the respiration

Add exogenous cytochrome $c$ and check the respiration; if respiration starts, the outer membrane is leaky. See troubleshooting for step 9 (mechanical and osmotic damage)

Follow carefully all the indicated critical steps to avoid the indicated contaminations; try washing glassware with isolation buffer, supplemented with EGTA Include $0.1 \%$ fatty acid free albumin in the EB; if this procedure works increase FCCP concentration since albumin binds reversibly to FCCP

Since at high doses FCCP is also an inhibitor of the respiratory chain, you can overcome this problem by titrating down the concentration of FCCP used

\section{ANTICIPATED RESULTS}

The goal of a mitochondrial preparation is to obtain a good amount of relatively pure, well coupled mitochondria. The quality of the obtained organelles can be checked by using oxygraphy to measure their oxygen consumption. For example, mitochondria isolated from mouse liver and energized with glutamate/malate respond to stimulation of ATPase by added ADP with a sixfold 
increase in the rate of oxygen consumption (Fig. 6b). This usually reflects mitochondria that are highly pure and intact. A closer look by conventional electron microscopy at the morphology and at the purity of the organelles isolated from other intracellular membranes revealed that most of the organelles displayed an intact inner and outer membrane and that the level of contamination by other membranes was kept to a minimum (Fig. 6a).

ACKNOWLEDGMENTS We thank Giuliano Dodoni and members of the Scorrano lab for helpful discussions. LS is an Assistant Telethon Scientist of the DulbeccoTelethon Institute. Research in his laboratory is supported by Telethon Italy; AIRC Italy; Compagnia di San Paolo; Human Frontier Science Program Organization; United Mitochondrial Disease Fund USA, Muscular Dystrophy Association USA.

COMPETING INTERESTS STATEMENT The authors declare that they have no competing financial interests.

Published online at http://www.natureprotocols.com

Reprints and permissions information is available online at http://npg.nature.com/ reprintsandpermissions

1. Dimmer, K.S. \& Scorrano, L. (De)constructing mitochondria: what for? Physiology (Bethesda) 21, 233-241 (2006).

2. Hogeboom, G.H., Schneider, W.C. \& Pallade, G.E. Cytochemical studies of mammalian tissues. I. Isolation of intact mitochondria from rat liver; some biochemical properties of mitochondria and submicroscopic particulate material. J. Biol. Chem. 172, 619-635 (1948).

3. Bensley, R.R. \& Hoerr, N. Studies on cell structure by the freezing-drying method VI. The preparation and properties of mitochondria. Anat. Rec. 60, 449-455 (1934).

4. Mitchell, P. \& Moyle, J. Chemiosmotic hypothesis of oxidative phosphorylation. Nature 213, 137-139 (1967).

5. Schatz, G., Haslbrunner, E. \& Tuppy, H. Deoxyribonucleic acid associated with yeast mitochondria. Biochem. Biophys. Res. Commun. 15, 127-132 (1964).

6. Nass, M.M. \& Nass, S. Intramitochondrial fibers with DNA characteristics. I. Fixation and electron staining reactions. J. Cell Biol. 19, 593-611 (1963).

7. Hallermayer, G., Zimmermann, R. \& Neupert, W. Kinetic studies on the transport of cytoplasmically synthesized proteins into the mitochondria in intact cells of Neurospora crassa. Eur. J. Biochem. 81, 523-532 (1977).

8. Palade, G.E. The fine structure of mitochondria. Anat. Rec. 114, 427-451 (1952).

9. Sorgato, M.C., Keller, B.U. \& Stuhmer, W. Patch-clamping of the inner mitochondrial membrane reveals a voltage-dependent ion channel. Nature 330, 498-500 (1987).

10. Liu, X., Kim, C.N., Yang, J., Jemmerson, R. \& Wang, X. Induction of apoptotic program in cell-free extracts: requirement for dATP and cytochrome $c$. Cell 86, 147-157 (1996).
11. Yang, J. et al. Prevention of apoptosis by Bcl-2: release of cytochrome $c$ from mitochondria blocked. Science 275, 1129-1132 (1997).

12. Scorrano, L. \& Korsmeyer, S.J. Mechanisms of cytochrome $c$ release by proapoptotic BCL-2 family members. Biochem. Biophys. Res. Commun. 304, 437-444 (2003).

13. Bossy-Wetzel, E., Barsoum, M.J., Godzik, A., Schwarzenbacher, R. \& Lipton, S.A. Mitochondrial fission in apoptosis, neurodegeneration and aging. Curr. Opin. Cell Biol. 15, 706-716 (2003).

14. Li, Z., Okamoto, K., Hayashi, Y. \& Sheng, M. The importance of dendritic mitochondria in the morphogenesis and plasticity of spines and synapses. Cell 119, 873-887 (2004).

15. St. John, J.C., Jokhi, R.P. \& Barratt, C.L. The impact of mitochondrial genetics on male infertility. Int. J. Androl. 28, 65-73 (2005).

16. Cipolat, S. et al. Mitochondrial rhomboid parl regulates cytochrome $c$ release during apoptosis via opa1-dependent cristae remodeling. Cell 126, 163-175 (2006).

17. Fontaine, E., Eriksson, 0., Ichas, F. \& Bernardi, P. Regulation of the permeability transition pore in skeletal muscle mitochondria. Modulation by electron flow through the respiratory chain complex I. J. Biol. Chem. 273, 12662-12668 (1998).

18. Frezza, C. et al. OPA1 controls apoptotic cristae remodeling independently from mitochondrial fusion. Cell 126, 177-189 (2006).

19. Meeusen, S., McCaffery, J.M. \& Nunnari, J. Mitochondrial fusion intermediates revealed in vitro. Science 305, 1747-1752 (2004).

20. Stahl, W.L., Smith, J.C., Napolitano, L.M. \& Basford, R.E. BRAIN MITOCHONDRIA: I. Isolation of Bovine Brain Mitochondria. J. Cell Biol. 19, 293-307 (1963).

21. Cannon, B. \& Lindberg, 0. Mitochondria from brown adipose tissue: isolation and properties. Methods Enzymol. 55, 65-78 (1979).

22. Mela, L. \& Seitz, S. Isolation of mitochondria with emphasis on heart mitochondria from small amounts of tissue. Methods Enzymol. 55, 39-46 (1979).

23. Siess, E.A. Different actions of mono- and disaccharides on rat liver mitochondria. Hoppe Seylers. Z. Physiol Chem. 364, 835-838 (1983).

24. Siess, E.A. Influence of isolation media on the preservation of mitochondrial functions. Hoppe Seylers. Z. Physiol Chem. 364, 279-289 (1983).

25. Eskes, R. et al. Bax-induced cytochrome c release from mitochondria is independent of the permeability transition pore but highly dependent on $\mathrm{Mg}^{2+}$ ions. J. Cell Biol. 143, 217-224 (1998).

26. Nicholls, D.G. \& Ferguson, S.J. Bioenergetics. Academic Press, London (2002). 